\title{
Efeito de baixo e alto nitrogênio em genótipos de milho cultivado em Tocantins
}

\section{Effect of low and high nitrogen in corn genotypes cultivated in Tocantins}

Weder Ferreira dos Santos ${ }^{1}$, Layanni Ferreira Sodré ${ }^{2}$, Joênes Mucci Pelúzio ${ }^{3}$, Rafael Marcelino da Silva ${ }^{4}$, Victor Hugo Gomes Sales ${ }^{5}$, Marllos Peres de Melo ${ }^{6}$

\section{RESUMO}

O presente estudo foi realizado com o objetivo de identificar genótipos de milho em cultivo sob alto e baixo nível tecnológico, em cultivares de Palmas, Estado do Tocantins. Para a realização da pesquisa foram utilizados doze genótipos de milho, que foram cultivados em ensaios de baixo e alto nível de nitrogênio $(N)$ em 0 e $120 \mathrm{~kg} \mathrm{ha}^{-1}$ na cobertura no Campus da Universidade Federal do Tocantins. O delineamento estatístico adotado foi o de blocos casualizados, com três repetições e 12 tratamentos. Foi empregado uma metodologia padrão para identificar os genótipos eficientes e responsivos ao N. Foi observado que os genótipos GEN 1, GEN 12 e GEN 11 são recomendados para produtores que adotam baixo nível tecnológico. Já genótipos GEN 5, GEN 6, GEN 4, GEN 9 e GEN 2, são indicados para produtores que utilizam alto nível tecnológico.

Palavras-chave: Zea mays. Estresse mineral. Cerrado. Produtividade.

\section{ABSTRACT}

The present study was carried out with the objective of identifying maize genotypes in cultivation under high and low technological level, in cultivars of Palmas, State of Tocantins. Twelve maize genotypes were used to perform the research, which were cultivated in low and high nitrogen (N) tests at 0 and $120 \mathrm{~kg} \mathrm{ha}^{-1}$ at the Campus of the Federal University of Tocantins. The statistical design adopted was randomized blocks, with three replicates and 12 treatments. A standard methodology was used to identify the genotypes efficient and responsive to $\mathrm{N}$. It was observed that genotypes GEN 1, GEN 12 and GEN 11 are recommended for producers who adopt a low level of technology. Genotypes GEN 5, GEN 6, GEN 4, GEN 9 and GEN 2 are indicated for producers who use a high level of technology.

Keywords: Zea mays. Mineral stress. Cerrado. Yield.
Doutor em Biodiversidade e

Biotecnologia.

Universidade

Federal do Tocantins.

E-mail:

eng.agricola.weder@gmail.com

2 Mestre em Agroenergia.

Universidade Federal do Tocantins.

3 Doutor em Genética e Melhoramento. Universidade Federal do Tocantins.

4 Bacharel em Agronomia. Universidade Federal do Tocantins.

5 Doutor em Biodiversidade e Biotecnologia. Instituto Federal do Amapá.

${ }^{6}$ Doutor em Produção Vegetal. Centro Universitário UNIRG. 


\section{INTRODUÇÄO}

A cultura do milho (Zea mays) apesar da baixa produtividade média no Brasil, de 3,7 to ha-1 ${ }^{-1}$ em inúmeras regiões do país, existem propriedades que apresentam médias maiores do que 10 ton ha-1 (PEIXOTO, 2016). No Estado do Tocantins a produtividade atual chega à média de 3,4 ton ha-1 (CONAB, 2016). Esses dados podem estar ligados ao potencial produtivo dessa cultura, que requer que suas exigências nutricionais sejam plenamente atendidas (FARINELLI \& LEMOS, 2012).

O nitrogênio $(\mathrm{N})$ é o nutriente exigido em maior quantidade pela cultura, sendo o maior responsável pela limitação da limita a produtividade de grãos (FORNASIERI FILHO, 2007). Assim, o desenvolvimento de genótipos eficientes no uso de $\mathrm{N}$ é uma estratégia para redução nos custos de produção e diminuição da dependência de insumos agrícolas.

A metodologia de Fageria \& Kluthcouski (1980) é bastante indicada para seleção de plantas quanto ao uso dos nutrientes e responsiva à sua aplicação. A eficiência na utilização do nutriente é, por sua vez, definida pela média da produtividade de grãos em baixo nível do nutriente, sendo a resposta à sua utilização obtida pela diferença entre a produtividade de grãos nos dois níveis de nutriente dividida pela diferença entre as doses (FIDELIS et al., 2014).

A eficácia dessa metodologia para a seleção de genótipos de plantas foi previamente descrita na literatura, sendo observada em trabalhos com a cultura do milho (FIDELIS et al., 2010; FIDELIS et al., 2014; SANTOS et al., 2016; SODRÉ et al., 2016), arroz (FIDELIS et al., 2013; PASSOS et al., 2015; ROTILI et al., 2010), feijão (SALGADO et al., 2012), e soja (COLOMBO et al., 2016).

Portanto, a seleção de genótipos eficientes na alta e baixa absorção de nutrientes presentes no solo é de suma importância para auxiliar os agricultores na seleção de genótipos específicos, além de escolher genótipos candidatos a serem usados nos programas de melhoramento de plantas. $\mathrm{O}$ uso desses genótipos pode reduzir, assim, o custo da produção, principalmente quando cultivados em solos de cerrado (COLOMBO et al., 2016; SODRÉ et al., 2016) que possuem baixa fertilidade química (OLIVEIRA et al., 2012).

Diante do exposto, o presente trabalho objetivou selecionar genótipos de milho para alto e baixo investimento em $\mathrm{N}$ em cultivares do Município de Palmas, Estado do Tocantins. 


\section{MATERIAIS E METODOS}

Para esse estudo, foram realizados dois ensaios de genótipos de milho no Centro Agrotecnológico da Universidade Federal do Tocantins (UFT), Campus de Palmas/TO, em Latossolo Vermelho Amarelo distrófico. Os ensaios foram instalados sob condições de alto $\mathrm{N}\left(120 \mathrm{~kg} \mathrm{ha}^{-1}\right)$ e baixo $\mathrm{N}\left(0 \mathrm{~kg} \mathrm{ha}^{-1}\right)$ em cobertura.

O delineamento experimental utilizado em cada ensaio foi em blocos casualizados com 12 tratamentos e três repetições. Os tratamentos foram constituídos por 12 genótipos de polinização aberta, sendo denominados de GEN 1 a GEN 12.

A parcela experimental foi representada por quatro linhas de cinco metros lineares, espaçadas por 0,90 m entre linhas. Na colheita, foram utilizadas as duas linhas centrais de cada fileira, descartando-se $0,50 \mathrm{~m}$ das extremidades.

O sistema de preparo de solo tipo convencional foi utilizado, com uma gradagem seguida do nivelamento da área. A adubação de pré-semeadura foi realizada manualmente, utilizando $300 \mathrm{~kg} \mathrm{ha}^{-1}$ de NPK de 5-25-15+0,5\% Zn, para todos os ensaios. Esta semeadura foi realizada a fim de se obter 55 mil plantas ha-1.

$\mathrm{A}$ adubação em cobertura foi realizada apenas com $\mathrm{N}$ nos estádios $\mathrm{V} 4 \mathrm{e} \mathrm{V} 8$, tendo a ureia como fonte de $\mathrm{N}$. A adubação no ambiente de baixo e alto $\mathrm{N}$ corresponde à menor $\mathrm{e}$ à maior faixa esperada de produtividade de grãos (RIBEIRO et al., 1999).

Os tratos culturais, como o controle fitossanitário contra doenças, pragas e plantas daninhas foram realizados de acordo com as recomendações técnicas da cultura (GALVÃO \& MIRANDA, 2004).

Nas duas fileiras centrais, de cada parcela foram colhidas as espigas, no estágio R6, que corresponde à maturidade fisiológica. Em seguida, as espigas foram debulhadas e os grãos acondicionadas em saco de papel, identificados e transportado para o Laboratório de Pesquisa Agropecuária da UFT - Campus de Palmas.

O rendimento de grãos foi analisado com base na massa de grãos de cada parcela corrigida para $13 \%$ de umidade e transformada em $\mathrm{kg} \mathrm{ha}^{-1}$.

Para a identificação de genótipos eficientes quanto ao uso do $\mathrm{N}$ e responsivos à sua aplicação, foi utilizado a metodologia proposta por Fageria \& Kluthcouski (1980). Por esta metodologia, a eficiência correspondente à média de rendimento de grãos de cada genótipo em baixo $\mathrm{N}$. 
A resposta à aplicação do nutriente para cada genótipo, foi oriunda da diferença de rendimento nos dois níveis de $\mathrm{N}$ (alto e baixo $\mathrm{N}$ ) dividido pela diferença entre os níveis de $\mathrm{N}$ utilizados em cobertura (Equação 1).

$$
\text { Resposta }=(\text { RG }(\text { AN-BN) }) /(\text { Nível }(\text { AN-BN }))
$$

Após serem tabulados, os dados de rendimento de grãos foram submetidos ao teste de normalidade. Em seguida, foi realizada análise de variância para cada ensaio (nível de N) e para análise conjunta de acordo com o critério da homogeneidade dos quadrados médios residuais dos ensaios.

As médias dos genótipos foram comparadas seguindo teste de grupos de Scott \& Knott (1974) a 5\% de significância.

As análises estatísticas foram realizadas utilizando o programa SISVAR, versão 5.5 (FERREIRA, 2008).

\section{RESULTADOS E DISCUSSAO}

Os dados apresentaram efeitos significativos a $(p<0,05)$ de probabilidade para ensaios, genótipo e interação com base na análise de variância (Tabela 1). A interação indica a existência de comportamento diferencial dos genótipos nos diferentes ensaios e com isso, foram realizados os desdobramentos. O coeficiente de variação indica boa precisão na condução dos experimentos (PIMENTEL-GOMES, 2009). Para a média geral do experimento de $5024 \mathrm{~kg} \mathrm{ha}^{-1}$ foi superior à média já descrita em literatura para o Tocantins $3436 \mathrm{~kg} \mathrm{ha}^{-1}$ descrita pelo boletim da CONAB (2016), segundo dados Carvalho et al. (2011) com produção anual de $4821 \mathrm{~kg} \mathrm{ha}^{-1}$.

Tabela 1. Análise de variância conjunta para rendimento de grãos $\left(\mathrm{kg} \mathrm{ha}^{-1}\right)$ de 12 genótipos de milhos cultivados em Palmas -TO.

\begin{tabular}{ccc}
\hline Fonte de variação & Grau de liberdade & Quadrado médio \\
\hline Ensaio & 1 & $52504005,60^{*}$ \\
Genótipos & 11 & $3147760,04^{*}$ \\
Ensaio*Genótipo & 11 & $541597,24^{*}$ \\
Repetição (ensaio) & 4 & 617806,68 \\
Resíduo & 44 & 150604,85 \\
\hline Coeficiente de variação (\%) & 7,72 \\
Média Geral (kg ha $\left.{ }^{-1}\right)$ & 5024 \\
\hline
\end{tabular}

\footnotetext{
*: significativo pelo teste $\mathrm{F}$ a $5 \%$.
} 
O rendimento de grãos (Tabela 2) variou de $3105 \mathrm{~kg} \mathrm{ha}^{-1}$ (baixo N; GEN 9) a $7336 \mathrm{~kg}$ ha $^{-1}$ (alto N; GEN 8), valores próximos aos encontrados por Carvalho et al. (2011) em 32 híbridos de milho do Tocantins.

A média do ensaio em Alto $\mathrm{N}$ (5878 $\mathrm{kg} \mathrm{ha}^{-1}$ ) foi superior quando comparada ao ensaio de Baixo N (4170 $\left.\mathrm{kg} \mathrm{ha}^{-1}\right)$. Apenas o GEN 11 apresentou comportamento similar em ambos os ensaios, enquanto os demais genótipos, apresentaram maiores rendimentos de grãos com alto N. Segundo Carvalho et al. (2011), o aumento do $\mathrm{N}$ em cobertura promoveu maiores produtividades, o que foi observado no presente estudo.

$\mathrm{Na}$ tabela 2 onde são apresentadas as medias de rendimento de grãos $\left(\mathrm{kg} \mathrm{ha}^{-1}\right)$, no ensaio de baixo $\mathrm{N}$ houve uma variação de $5596 \mathrm{~kg} \mathrm{ha}^{-1}$ (GEN 12) a $3105 \mathrm{~kg} \mathrm{ha}^{-1}$ (GEN 9). No grupo com as maiores médias estão os GEN 10 e GEN 12 e no grupo com as menores médias os GEN 2, GEN 3, GEN 4, GEN 5, GEN 6, GEN 7 e GEN 9. Médici et al. (2004) afirmaram que a seleção de genótipos de milho sob baixo $\mathrm{N}$ melhora a eficiência com que o N é utilizado na produção de grãos.

Tabela 2. Médias de rendimento de grãos $\left(\mathrm{kg} \mathrm{ha}^{-1}\right)$ em 12 genótipos de milho cultivados com dois níveis de $\mathrm{N}$ em Palmas/TO.

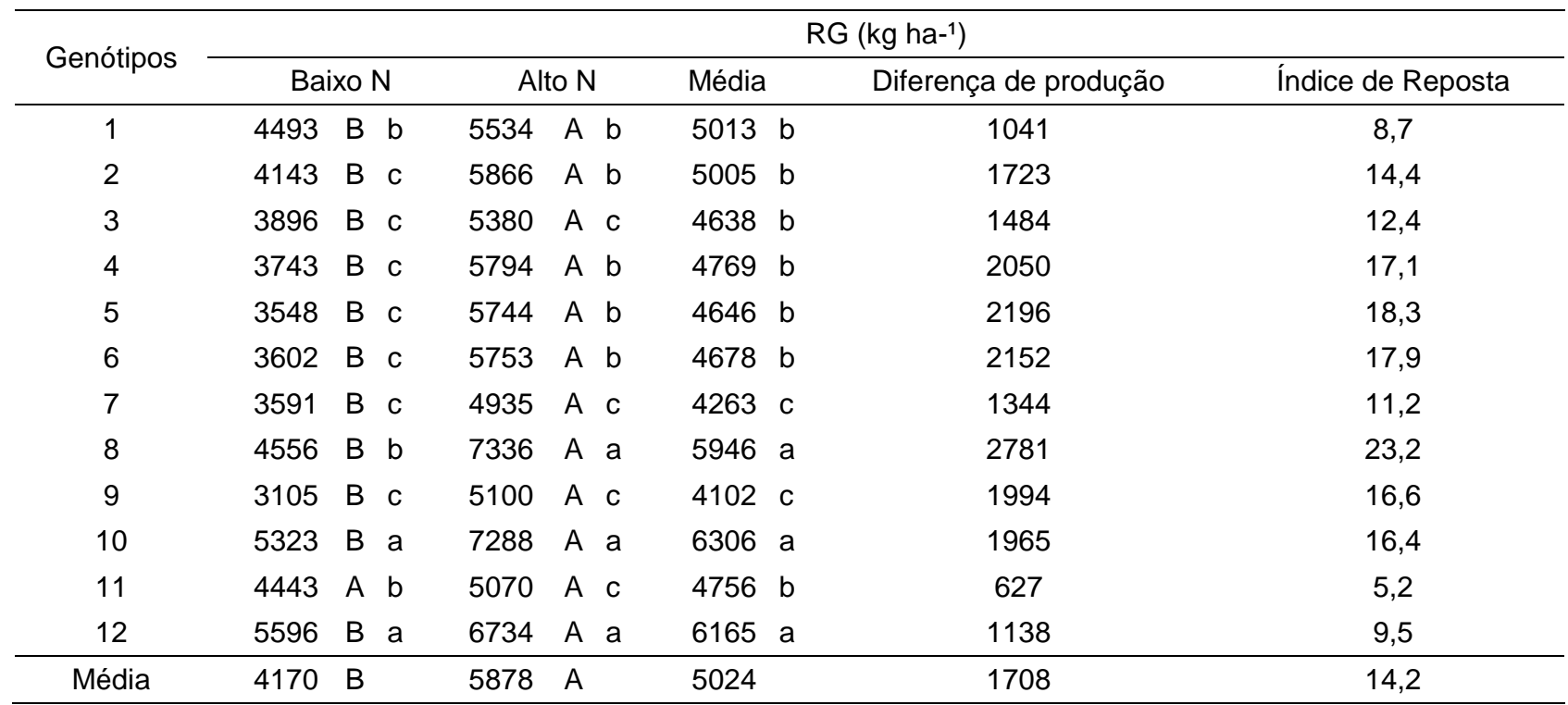

Médias seguidas por mesma letra maiúscula na linha e minúscula na coluna, pertencem a um mesmo grupo, de acordo com o critério de agrupamento de Scott \& Knott (1974) a 5\% de significância. Alto N=120 kg ha-1; Baixo $\mathrm{N}=0 \mathrm{~kg} \mathrm{ha}^{-1}$

No ensaio com alto $\mathrm{N}$, as médias variaram de $4935 \mathrm{~kg} \mathrm{ha}^{-1}$ (GEN 7) a $7336 \mathrm{~kg} \mathrm{ha}^{-1}$ (GEN 8). No grupo com as maiores médias estão os GEN 8, GEN 10 e GEN 12 enquanto as menores médias foram correspondentes aos genótipos GEN 3, GEN 7, GEN 9 e GEN 11 (Tabela 2). 
A média dos genótipos variou entre $6306 \mathrm{~kg} \mathrm{ha}^{-1}$ (GEN 10) a $4102 \mathrm{~kg} \mathrm{ha}^{-1}$ (GEN 9). As maiores médias de rendimento grãos foram encontradas nos genótipos GEN 8, GEN 10 e GEN 12, com as menores médias encontram-se os GEN 7 e GEN 9 (Tabela 2).

Com a metodologia de Fageria \& Kluthcouski (1980) usada no presente estudo, cinco genótipos (GEN 8, GEN 10, GEN 1, GEN 11 e GEN 12) apresentaram maiores eficiências com uso de N. Estes genótipos, estão apresentados nos quadrantes I e IV da figura 1. Estes resultados estão em concordância com os encontrados nos estudos de Santos et al. (2016) e Sodré et al. (2016), onde os autores também verificaram comportamento diferencial nos genótipos quando submetidos aos níveis diferentes de $\mathrm{N}$.

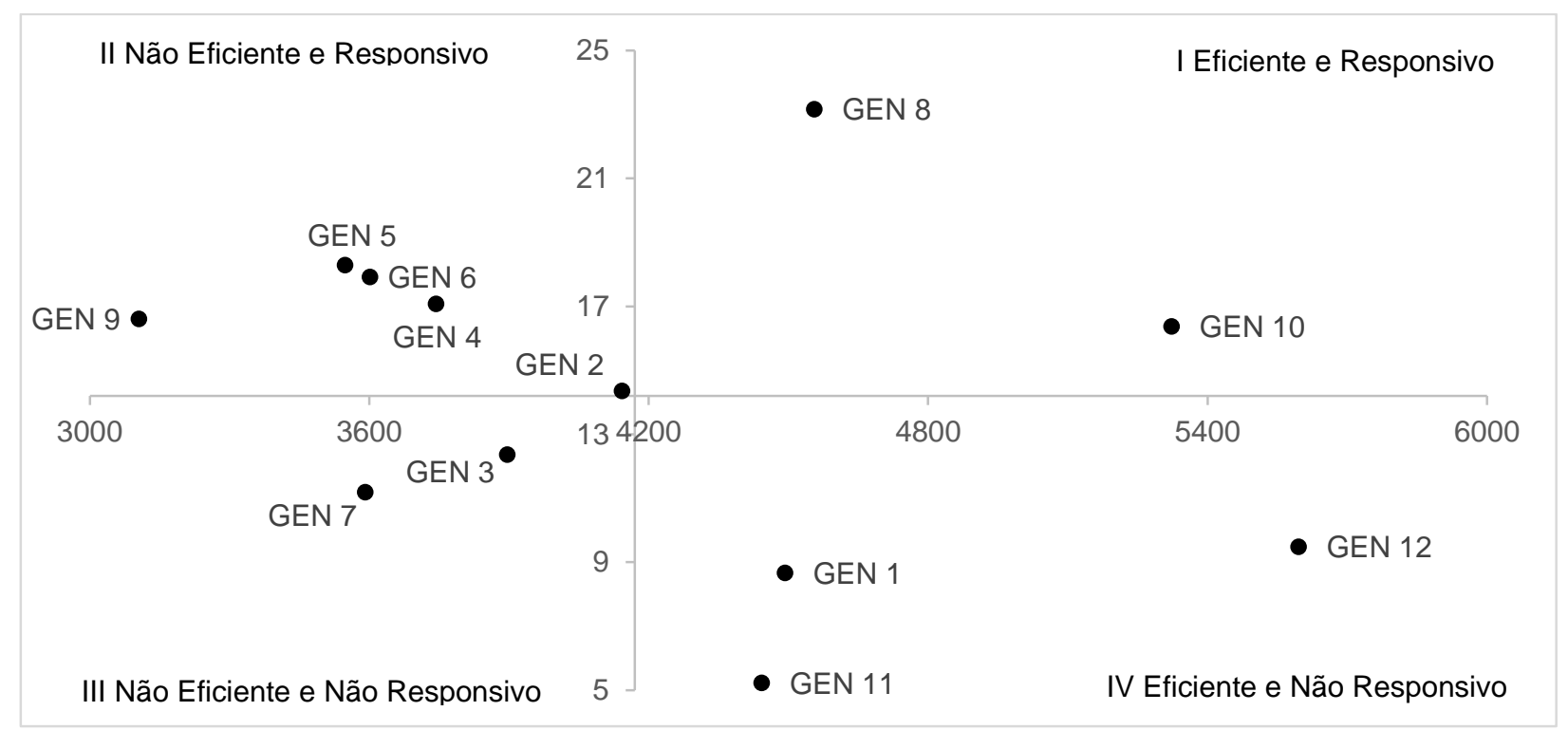

Figura 1. Eficiência no uso e resposta à aplicação de nitrogênio em genótipos de milho cultivados em Palmas/TO.

Os índices de respostas apresentaram sete genótipos responsivos (GEN 9, GEN 6, GEN 5, GEN 4, GEN 2, GEN 8, e GEN 10) todos com valores superiores ao valor médio $(14,2)$. O genótipo GEN 8 apresentou o maior valor de responsividade em comparação aos demais (Tabela 2). Genótipos que apresentam alto índice de resposta, tornam-se interessantes, pois respondem ao incremento do $\mathrm{N}$ quando promove-se a melhoria do ambiente (FIDELIS et al., 2012).

Ressalta-se que o GEN 8 e o GEN 10 além de responsivos, são também eficientes ao $\mathrm{N}$ (Figura 1), o que demonstra adaptação destes materiais em ambientes de baixa (BN) e alta disponibilidade de N (AN) (I quadrante). Portanto, recomendados estes genótipos para 
o cultivo em propriedades que adotam desde o baixo até o alto nível tecnológico, o uso desses genótipos, conforme recomenda Santos et al. (2016).

Por outro lado, os genótipos GEN 9, GEN 5, GEN 6, GEN 4 e GEN 2 por terem baixo rendimento de grãos em $\mathrm{BN}$, foram considerados não eficientes, embora sejam genótipos responsivos (II quadrante) (Figura 1). Estes genótipos são indicados para serem utilizados pelos produtores com elevado nível tecnológico (FIDELIS et al., 2012).

Os genótipos GEN 3 e GEN 7, apresentaram, por sua vez, baixo rendimento de grãos no ambiente BN (inferior à média geral, $4170 \mathrm{ha}^{-1}$ ) e os piores índices de resposta ao $\mathrm{N}$, sendo considerados, não responsivos e não eficientes (III quadrante) (Figura 1). Estes genótipos não são, portanto, indicados para nenhum tipo de propriedades agrícolas (FIDELIS et al., 2011).

Os genótipos GEN 1, GEN 11 e GEN 12 apresentaram alto rendimento de grãos no ambiente BN, maior que a média geral $\left(4170 \mathrm{~kg} \mathrm{ha}^{-1}\right)$ e os piores índices de resposta ao $\mathrm{N}$, sendo considerados não responsivos e eficientes (IV quadrante) (Figura 1). Os genótipos deste grupo são recomendados para propriedades com nível tecnológico baixo (FIDELIS et al., 2010; FIDELIS et al., 2014).

\section{CONCLUSÖES}

De acordo com os dados desse estudo, detectamos que a metodologia de Fageria \& Kluthcouski (1980), mostrou-se eficaz em discriminar genótipos responsivos e eficientes em cultivares de milhos do Estado do Tocantins.

E os genótipos de milho GEN 2, GEN 4, GEN 5, GEN 6 e GEN 9, são indicados para produtores que utilizam alto nível tecnológico.

Os genótipos GEN 1, GEN 11 e GEN 12 são recomendados para o cultivo em propriedades que adotam baixo nível tecnológico, o que corresponde à maioria das propriedades do Tocantins.

\section{REFERÉNCIAS}

CARVALHO, E.V.; AFFÉRRI, F.S.; PELUZIO, J.M.; LEÃO, F.F.; CANCELLIER, L.L.; DOTTO, M.A. Eficiência e uso do nitrogênio em híbridos experimentais de milho do programa de melhoramento da Universidade Federal do Tocantins. Bioscience Journal, v.27, n.3, p.392-403, 2011.

COLOMBO, G.A.; PELÚZIO, J.M.; PIRES, L.P.M.; DARONCH, D.J.; MACHADO FILHO, G.C. Eficiência do uso de fósforo de cultivares de soja em condições de cerrado tocantinense. Journal of Bioenergy and Food Science, v.3, n.1, p. 42-49, 2016. 
CONAB - Companhia Nacional de Abastecimento. Acompanhamento da safra Brasileira de Grãos, v. 4 Safra 2016/17 - Terceiro levantamento. Brasília: CONAB, 2016. Disponível em: <http://www.conab.gov.br/OlalaCMS/uploads/arquivos/16_12_22_12_08_27_boletim_ graos_dezembro_2016.pdf>. Acesso em: 22 jan. 2017.

FAGERIA, N.D.; KLUTHCOUSKI, J. Metodologia para avaliação de cultivares de arroz e feijão para condições adversas de solo. Brasília: EMBRAPA/CNPAF, 1980. 22p.

FARINELLI, R.; LEMOS, L.B. Nitrogênio em cobertura na cultura do milho em preparo convencional e plantio direto consolidados. Pesquisa Agropecuária Tropical, v.42, n.1, p.63-70, 2012.

FERREIRA, D.F. SISVAR: um programa para análises e ensino de estatística. Revista Symposium, v.6, p.36-41, 2008.

FIDELIS, R.R.; MIRANDA, G.V.; PELÚZIO, J.M.; GALVÃO, J.C.C. Classificação de populações de milho quanto à eficiência e resposta ao uso de fósforo. Acta Scientiarum Agronomy, v.32, n.2, p.241-246, 2010.

FIDELIS, R.R.; NASCIMENTO, L.C.; SANTOS, M.M.; SILVA, G.F.; TONELLO, L.P.; OLIVEIRA, T.C. Efeito da adubação fosfatada na qualidade fisiológica de sementes de arroz cultivadas em terras altas. Bioscience Journal, v.29, n.1, p.15-21, 2013.

FIDELIS, R.R.; ROTILI, E.A.; SANTOS, M.M.; BARROS, H.B.; MELO, A.V.; DOTTO, M. Eficiência no uso de nitrogênio em cultivares de arroz irrigado. Revista Brasileira de Ciências Agrárias, v.6, n.4, p.622-626, 2011.

FIDELIS, R.R.; ROTILI, E.A.; SANTOS, M.M.; BARROS, H.B.; RODRIGUES, A.M. Eficiência quanto ao uso e resposta à aplicação de nitrogênio de cultivares de arroz em solos de terras altas no Sul do Estado de Tocantins, safra 2007/2008. Bioscience Journal, v.28, n.3, p.432-438, 2012.

FIDELIS, R.R.; SANTOS, M.M.; SANTOS, G.R.; SILVA, R.R.; VELOSO, D.A. Classificação de populações de milho quanto a eficiência e resposta ao uso de fósforo. Pesquisa Agropecuária Pernambucana, v.19, n.2, p.59-64, 2014.

FORNASIERI FILHO, D. Manual da cultura do milho. Jaboticabal: Funep, 2007.

GALVÃO, J.C.C.; MIRANDA, G.V. Tecnologias de Produção de Milho. Viçosa: UFV, 2004. p.336.

MÉDICI, L.O.; PEREIRA, M.B.; LEA, P.J.; AZEVEDO, R.A. Diallel analysis of maize lines with contrasting responses to applied nitrogen. Journal of Agricultural Science, v.142, n.05, p.535-541, 2004.

OLIVEIRA, T.C.; SILVA, J.; SALGADO, F.H.M.; SOUSA, S.A.: FIDELIS, R.R. Eficiência e resposta à aplicação de fósforo em feijão comum em solos de cerrado. Revista Verde, v.7, n.1, p.16-24, 2012.

PASSOS, N.G.; SOUSA, S.A.; LOPES, M. B.S.; VARAVALLO, M.A.; OLIVEIRA, T.C.; FIDELIS, R.R. Eficiência no uso de nitrogênio em genótipos de arroz em solos de várzea tropical do Estado do Tocantins. Revista Agro@mbiente On-line, v.9, n.1, p.8-16, 2015.

PEIXOTO, C.M. Avanços tecnológicos da cultura do milho no brasil. 2016. Disponível 
em: <http://www.diadecampo.com.br/zpublisher/materias/Materia.asp?id=23562\&secao= Sementes\%20e\%20Mudas>. Acesso em: 25 jan. 2017.

PIMENTEL-GOMES, F. Curso de estatística experimental. 15. ed. Piracicaba: FEALQ, 2009. 451p.

RIBEIRO, A.C.; GUIMARÃES, P.T.G.; ALVAREZ, V.V.H. Recomendação para o uso de corretivos e fertilizantes em Minas Gerais - 5a Aproximação. Viçosa: UFV, 1999. 359p.

ROTILI, E.A.; FIDELIS, R.R.; SANTOS, M.M.; BARROS, H.B.; PINTO, L.C. Eficiência do uso e resposta à aplicação de fósforo de cultivares de arroz em solos de terras altas. Bragantia, v.69, n.3, p.705-710, 2010.

SALGADO, F.H.M.; SILVA, J.; OLIVEIRA, T.C.; BARROS, H.B.; PASSOS, N.G.; FIDELIS, R.R. Eficiência de genótipos de feijoeiro em resposta à adubação nitrogenada. Pesquisa Agropecuária Tropical, v.42, n.4, p.368-374, 2012.

SANTOS, W.F.; PELÚZIO, J.M.; AFFÉRRI, F.S.; SODRÉ, L.F.; HACKENHAAR, C.; REINA, E.; MACÊDO, D.A. Eficiência e resposta ao uso de nitrogênio em genótipos de milho para rendimento de proteína. Revista Tecnologia \& Ciência Agropecuária, v.10, n.4, p.6-11, 2016.

SCOTT, A.J.; KNOTT, M.A. Cluster analysis method for grouping means in the analysis of variance. Biometrics, v.30, p.507-512, 1974.

SODRÉ, L.F.; ASCÊNIO, S.D.; PELÚZIO, J.M.; AFFÉRRI, F.S.; SANTOS, W.F.; CARVALHO, E.V. Cultivo para alto e baixo nitrogênio em genótipos de milho no Tocantins visando a produção de óleo. Revista de Agricultura, v.91, n.2, p.174-183, 2016. 